\title{
Addressing the complex challenge of unmet need: a moral and equity imperative?
}

\author{
Anna Matheson, Lis Ellison-Loschmann
}

$\mathrm{I}$ $\mathrm{f}$ unmet need is not a measure of the effectiveness of a health system, how do we really know how well it is doing and how to improve it? There is plenty of support in the literature for unmet need to be recognised as a key indicator of the success of a health system-however, to date, the lack of effective translation of this evidence into action has drawn criticism. ${ }^{1,2}$

In New Zealand, despite continual system reform and possessing a number of the foundations for an enviable health system, it appears that many New Zealanders' health needs are still not being met. Recently the New Zealand Health Survey (NZHS) for $2014 / 15$ reported $29 \%$ of adults had experienced some form of unmet need for primary care in the previous 12 months. ${ }^{3}$ This figure is high even against other countries with comparable health systems, including the UK and Canada (5\% and $21 \%$ respectively). ${ }^{4}$ Furthermore, unmet need is implicated as a significant driver of health inequalities. It is well established that Māori experience unequal access to healthcare at all levels of service provision. ${ }^{3,5,6}$ The comparable figure for Māori experiencing unmet primary healthcare need (PHN)-as reported in the above 2014/15 NZHS—was 39\% (MOH, 2016).

Unmet need and its unequal burden are a cost to the economy-it does not result in savings but rather shifts costs within, and creates costs outside, the health system. Indeed, there is a strong case to be made that addressing unmet need could result in substantial savings. As Mills and colleagues point out, there are long-term benefits to society of addressing the unmet health needs of Māori children. ${ }^{7}$
So, we have indications that there is significant unmet need as well as growing argument that we need better measurement, particularly within secondary care. The two articles in this issue highlight some of the challenges of both measuring and understanding unmet need. First, Bagshaw and colleagues ${ }^{8}$ describe a pilot study conducted in Auckland and Christchurch trialling different methods (GP survey and a population survey involving online, face-to-face or telephone interviews) for undertaking a national survey of unmet secondary healthcare need (SHN) and estimating the prevalence of unmet SHN, to inform sample size calculations. Estimating a prevalence of unmet PHN at $29 \%$ and unmet SHN at 9\%, the authors suggest an approach similar to that used for the NZHS was most promising in terms of meeting the challenges posed by a survey of this kind. Interestingly, the authors conclude that "asking GPs to record unmet need for secondary health care at clinical presentation was not worthwhile because very few GPs participated" (in this pilot).

The second article by Inglis and colleagues ${ }^{9}$ reported a study for determining the 'real' unmet need related to the implementation of a triage system for elective hip and knee referrals in Canterbury. They found that $43 \%$ of hip and $54 \%$ of knee patients were not able to move beyond the initial triage process, which rations access to specialist appointments. This finding was at odds with $\mathrm{MOH}$ figures that show $0.6 \%$ of patients are waiting longer than the government target of four months for hip and knee surgery. With an estimate of close 
to $50 \%$ of unmet in the community, this study suggests that by aiming for the health target through local implementation, the real burden of unmet need is obscured. This is an interesting illustration of how general targets influence actions towards achieving the goal-at the expense of real and more meaningful outcomes. It also shows the diversity of actions that may occur locally, as well as the potential value of having greater local knowledge for improving real health outcomes.

The substance of these two articles raises some important questions for measuring and understanding unmet need including whether there is any real rationale for separating unmet need in primary care from that within secondary care. Health systems are complex systems ${ }^{10}$ and integrated care models recognise this implicitly. ${ }^{11}$ Unmet need in primary care influences unmet need in secondary care-particularly in respect of increasing health inequalities. The evidence of the critical role of GPs in influencing access to secondary care underscores this, despite their low participation in the Bagshaw et al study $^{8}$ alongside the potential for GPs to be reluctant to refer patients due to the high threshold of acceptance for treatment as noted by Inglis et al, ${ }^{9}$ as does the increasing evidence of the utility of employing 'navigators' to facilitate greater access to and through the health system for population groups who experience multiple barriers..$^{12,13}$

Here we offer up two-not mutually exclusive-potential ways forward for addressing some of the challenges identified here.

First, is it time that we looked past more traditional measurement methodologies and moved towards those strategies which explicitly attempt to take account of local context—one example being Qualitative Comparative Analysis (QCA). ${ }^{14}$ The strength of this approach, and those similar, would be to enable some measure of the burden of unmet need, as well as to gather information on the characteristics of unmet need, in context, that may be amenable to responsive action. The example of the locally implemented triage system in Canterbury ${ }^{9}$ illustrates this need to acknowledge the vagaries of local actions.

A second potential way forward is for adaptive processes and practices to become core features of health systems. If we recognise the health system as complex, where the levels of care are interrelated, then the need for health organisations to be forward as learning and adaptive organisations becomes clearer. This would enhance their ability to respond to unmet need through their actions of providing services. Limited examples of these types of adaptations currently occurring in primary care, include PHOs and other providers extending outreach services to homes or other settings, changing hours of practice to accommodate people's employment situations and promoting culturally safe practice. ${ }^{15,16}$ Could such adaptive practices be extended, and become commonplace, in primary care? And could secondary care organisations also move in this direction? The coordination and responsiveness of health funding contracts is one mechanism that can encourage adaptation over time, while how health targets are implemented could be another. General targets can be useful for guiding priorities, but their ability to obscure real outcomes needs to be acknowledged. ${ }^{17}$ They are useful as long as there is also an ability to learn and adapt where the reality of outcomes misses the target.

We agree with Keene and colleagues that the health system requires greater funding to a level that enables New Zealanders' healthcare needs to be met. ${ }^{18}$ However, we would also suggest that some kind of reform is needed towards better integration and greater recognition of the importance of focussing on unmet need. Is it possible to have an adaptive health system that responds to different needs differently and learns from its past actions? Undoubtedly, more attention must be given to prioritising, measuring and responding to unmet need. There is a moral and equity imperative to ensure this happens. 


\section{Competing interests:}

Nil.

Author information:

Anna Matheson, School of Public Health, Massey University, Wellington; Lis Ellison-

Loschmann, Centre for Public Health Research, Massey University, Wellington.

Corresponding author:

Dr Anna Matheson, School of Public Health, Massey University, 63 Wallace Street, Mt Cook, Wellington 6140.

a.g.matheson@massey.ac.nz

URL:

http://www.nzma.org.nz/journal/read-the-journal/all-issues/2010-2019/2017/vol-130-no-145224-march-2017/7190

\section{REFERENCES:}

1. Gauld R, Raymont A, Bagshaw PF, Nicholls MG, Frampton CM. The importance of measuring unmet healthcare needs. New Zealand Medical Journal. 2014; 127(1404).

2. Rodney AM, Hill PS. Achieving equity within universal health coverage: a narrative review of progress and resources for measuring success. International Journal of Equity in Health. 2014; 13(72).

3. Ministry of Health. Annual Update of Key Results 2015/16: New Zealand Health Survey. Wellington: Ministry of Health; 2016.

4. OECD. Health at a Glance 2015: OECD Indicators. Paris, http:// dx.doi.org/10.1787/ health_glance-2015-en: OECD Publishing; 2015.

5. Schoen C, Blendon R, DesRoches C, Osborn R, Doty M, Downey D. New Zealand adults' health care system views and experiences, 2001: findings from the Commonwealth Fund 2001 International Health Policy Survey. http:// www.cmwf.org/usr_doc/ nz_sb_553.pdf; 2002.

6. Ministry of Health. A Portrait of Health. Key Results of the 2006/07 New Zealand Health Survey. Wellington; 2008.
7. Mills C, Reid P, Vaithianathan R. The cost of child health inequalities in Aotearoa New Zealand: a preliminary scoping study. BMC Public Health. 2012; 12(384).

8. Bagshaw P, Bagshaw $S$, Frampton C, Gauld R, Green T, Harris C, et al. Pilot study of methods for assessing unmet secondary health care need in New Zealand. New Zealand Medical Journal. 2017; 130(1452):23-38.

9. Inglis $\mathrm{T}$, Armour P, Inglis G, Hooper G. Rationing of Hip and Knee Referrals in the Public Hospital: The True Unmet Need New Zealand Medical Journal. 2017; 130(1452):39-48.

10. Plsek PE, Greenhalgh T. Complexity science: The challenge of complexity in health care. British Medical Journal. 2001; 323.

11. Starfield B. Primary care: an increasingly important contributor to effectiveness, equity, and efficiency of health services. Gaceta Sanitaria; 2012.

12. Natale-Pereira A, Enard K, Nevarez L, Jones L. The role of patient navigators in eliminating health disparities. Cancer. 2011; 117(15 suppl):3541-50.

13. CBG Health Research Ltd. Final report: Improving access to services for vulnerable populations. DHB NZ Research Fund; 2011.

14. Blackman T, Wistow J, Byrne D. A Qualitative Comparative Analysis of factors associated with trends in narrowing health inequalities in England. Social Science and Medicine. 2011; 72:1965-74.

15. Thomson R, Crengle $S$, Lawrenson R. Improving participation in breast screeing in a rural general practice with a predominantly Māori population. New Zealand Medical Journal. 2009; 122(1291):39-47.

16. Boulton A, Tamehana J, Brannelly T. Whanau-centred health and social service delivery in New Zealand. Mai Journal A New Zealand Journal of indigenous scholarship. 2013; 2(1):18-31.

17. Wismar M, Busse R. Outcome-related health targets-political strategies for better health outcomes A conceptual and comparative study (part 2). Health Policy. 2002; 59.

18. Keene L, Bagshaw $P$, Nicholls G, Rosenberg B, Frampton CM, Powell I. Investment in health can mitigate health costs and improve the quality of life New Zealand Medical Journal. 2016; 129(1435). 
Reproduced with permission of the copyright owner. Further reproduction prohibited without permission. 